\title{
LA ÉTICA DE LAS PROFESIONES EN LA FORMACIÓN UNIVERSITARIA
}

Agustín Domingo Moratalla*

\section{Introducción}

La aceleración de los cambios tecnológicos y la dimensión fundamentalmente práctica del conocimiento científico impiden tiempos de reflexión para evaluar los fines y valores últimos a los cuales sirve. Además, desde los propios científicos se ha producido la voz de alarma sobre todo en cuestiones de biotecnología, bioética, ética medio-ambiental, etc. ¿Está en juego la especie humana? ¿Podemos confundir dimensión practica, utilitaria y ética de los conocimientos? ¿ No nos estaremos moviendo en una pendiente resbaladiza cuyos fines desconocemos? ¿Hemos llegado a pensar todo el proceso ético, social y político en el que se sitúa el conocimiento humano? ¿No estaremos jugando a ser dioses cuales nuevos Prometeos? ¿Quién puede frenar la ciencia y sus aplicaciones: el derecho, la ética, la propia conciencia de los profesionales? ¿Es necesario una ética de frenos, una ética de miedos o una ética de responsabilidades solidarias?

Quienes tenemos responsabilidades educativas y formativas también tenemos que preguntamos ¿qué modelo de profesionales están generando nuestros centros? ¿ ante qué tipo de sociedad se enfrentan? ¿han tomado conciencia que son 'profesionales del conocimiento' por su

\footnotetext{
* Universidad de Valencia, España.
} 


\section{AGUSTÍN DOMINGO}

formación técnica? ¿qué tipo de ética les estamos transmitiendo o están aprendiendo en nuestros centros? Los problemas desbordan la buena voluntad de un profesor o departamento para afectar a toda la estructura institucional y formativa. Una de las respuestas más atractivas es la que se ha producido desde las éticas aplicadas y éticas profesionales. En ellas queremos detenemos porque nos preocupa evaluar la calidad de nuestro propio trabajo profesional. Y sobre todo porque las propias profesiones de la sociedad civil nos están exigiendo nuevos estilos formativos.

La respuesta a estas preguntas dependerá de cómo entendamos las relaciones entre la sociedad y la universidad. De hecho, éste será el marco en el que nos movamos para poder responder con precisión a las preguntas que nos hemos planteado. Ahora bien, no nos conformamos con una reflexión general sobre las exigencias de la sociedad actual a la universidad sino que hemos descendido unos cuantos escalones de concreción y en lugar de hablar de 'sociedad', en general, hablaremos de ‘éticas profesionales’. Esto significa que:

- No es sobre las relaciones entre cultura y sociedad. Somos conscientes que las sociedades multiculturales son un desafío radical a los sistemas educativos en general y, sobre todo, a las instituciones universitarias. Sin embargo, si buscamos abrir procesos de evaluación permanente en nuestras prácticas educativas tenemos que descender a los niveles más locales y cotidianos donde estas prácticas se ejercen.

- No es sobre las relaciones entre universidad y sociedad civil. Somos conscientes que las instituciones educativas son un desafío radical a cualesquiera de las fórmulas por las que se haya erigido un centro universitario. Tanto los centros de titularidad privada como los centros de titularidad pública se legitiman ante la opinión pública cuando desarrollan un servicio educativo de calidad.

- No es sobre las relaciones entre la capacitación profesional de forma individual y los centros universitarios. Somos cons- 
cientes que la formación de buenos profesionales debe ser uno de los objetivos centrales de todo centro universitario. Ahora bien, los problemas éticos no son exclusivos de un área de conocimiento o de trabajadores con un determinado perfil profesional. A diferencia de otras instituciones sociales que pueden contribuir al desarrollo profesional específico, la contribución de los centros universitarios debe tener un carácter propio.

- No es sobre las relaciones entre la sociología de las profesiones y las facultades o escuelas universitarias. Por su función mediadora entre la investigación científica, la docencia especializada y la cultura de los pueblos, la universidad no puede ser únicamente una respuesta institucional a las demandas de capacitación y formación que tiene una determinada sociedad. La universidad no es únicamente un centro de capacitación y prospectiva profesional, para eso hay otros centro de formación académica como los que erigen los bancos, las empresas o las iglesias. La universidad no sólo gestiona conocimiento sino que lo conmemora y produce.

Sí será sobre las éticas profesionales, y no sólo porque hasta ahora éstas últimas les han preocupado más a los sociólogos y los propios profesionales, ${ }^{1}$ sino porque éstas pueden:

a) desvelar los bienes internos de las prácticas profesionales cotidianas,

b) realizar una mediación privilegiada entre los proyectos personales de felicidad y los mínimos compartidos de justicia,

c) plantear el problema de los equipos profesionales y la identificación de los profesionales con la moral institucional o corporativa.

d) contribuir a despertar, clarificar y perfilar los factores vocacio nales que intervienen en el ejercicio responsable de las profesiones.

${ }^{1}$ A. Hortal, “Ética de las profesiones”, Diálogo filosófico, 1993, 205-22. 
AGUSTÍN DOMINGO

\section{Vocación educativa y ética profesional}

\subsection{Vocación y profesión}

Uno de los más brillantes analistas de las sociedades modernas fue Max Weber. En su famoso libro La ética protestante y el espíritu del capitalismo señala la relación que existe entre una cosmovisión religiosa en la que es importante la idea de vocación y los orígenes de la sociedad moderna:

En la palabra ‘profesión’ (Beruf), como quizá más adelante en la inglesa calling, hay cuando menos una reminiscencia religiosa: la idea de misión impuesta por Dios... en su sentido actual la palabra nació precisamente de traducciones de la Biblia, y no precisamente del espíritu del texto original, sino del espíritu del traductor... es producto de la Reforma. Ni en la Edad Media ni en la Antigüedad se dieron los supuestos para esa estimación del trabajo cotidiano en el mundo que implica la idea de profesión... Lo absolutamente nuevo era considerar que el más noble contenido de la conducta moral consistía justamente en sentir como un deber el cumplimiento de la tarea profesional en el mundo. Tal era la consecuencia inevitable del sentido, por así decirlo, sagrado del trabajo. ${ }^{2}$

Si nos detenemos en el significado de los términos que hemos destacado, las relaciones entre vocación y profesión:

- están ligadas a una cosmovisión religiosa,

- suponen una re-sacralización del trabajo,

- construyen el mundo,

- el trabajo se siente como deber.

${ }^{2}$ M. Weber, La ética protestante y el espíritu del capitalismo, 1985, Barcelona, Orbis, trad. L. Legaz, p. 81-103. 
Esta estrecha relación en la que aparecen vocación y profesión ya no puede plantearse en los mismos términos que lo hacía Max Weber, no sólo porque las sociedades modernas son sociedades en mayor o menor medida secularizadas, sino porque la vocación parece ser una cuestión poco importante en los estudios sobre las profesiones. Unos estudios en los que se presta más atención a los aspectos externos, funcionales u organizativos de las ocupaciones que a las dimensiones ‘internas', 'motivacionales' o ‘existenciales'. En manos de la psicología social o de la sociología de las organizaciones, la vocación se ha convertido en un tema 'marginal', difícil de cuantificar y delimitar en los estudios ‘científicos’ de las organizaciones laborales. En este sentido, se ha producido una psicologización de la vocación que la ha segregado de la reflexión sobre la ética de las profesiones.

Esto no quiere decir que haya desaparecido por completo el carácter 'sagrado' que se otorga a la idea de servicio que hay en el concepto de profesión. De hecho, las profesiones más relevantes mantienen sus juramentos o promesas para quienes pueden entrar a formar parte de ellas. A muchos profesionales, como los médicos, los jueces, los políticos o los abogados se les exige 'profesar' un determinado código deontológico, es decir, confesar, prometer o dar testimonio público (del latín profiteri). A diferencia de los oficios en los que no se exige esta calidad moral -pero sí el cumplimiento de la ley- el 'profesional' sí tiene esta exigencia de integridad moral. Los contextos de secularización no han privado de cierto carácter moral sagrado a estas profesiones. ${ }^{3}$

Ahora bien, quizá tengamos que empezar a recuperar la vinculación que existía entre vocación y profesión pero en un contexto social secularizado. La vocación ya no puede plantearse desde la perspectiva de la necesidad, sino desde la perspectiva de la libertad; es decir, no podemos plantear éticamente la vocación como respuesta a una llamada que Dios nos hace para 'cumplir con nuestros deberes profesionales', como si la persona verdaderamente vocacionada fuera aquella que

${ }^{3}$ Cfr. La sociedad española de 1995, Informe de la Fundación Encuentro, 1996, Madrid, p. 5. 


\section{AGUSTÍN DOMINGO}

realiza una misión encomendada por otro. La perspectiva de la libertad plantea la vocación en términos de responsabilidad; aunque no sea Dios el que llama o asigna una misión, hay un telos personal que realizar. Nos encontramos ante un profesional ‘vocacionado’ cuando nos encontramos con un profesional que 'responde desde sí'. No sólo es un trabajador que responde por sí mismo, sino desde sí mismo, es decir, desde un proyecto de vida en el que se inscribe una ocupación profesional.

Responde de sí mismo, esto es, de las actividades que él realiza; pero también responde desde sí mismo, lo que significa, desde un proyecto de vida que comparte con otros. ¿Entonces podemos decir que un profesional vocacionado es un profesional responsable? Evidentemente no todos los profesionales responsables son profesionales vocacionados, pero sí es cierto que todo profesional vocacionado debe ser un profesional responsable. ¿Qué añade la vocación a la responsabilidad profesional? Añade la pregunta por la coherencia o adecuación entre el proyecto de vida personal y el proyecto de vida profesional. Como hemos señalado en otro lugar, la pregunta por la vocación sigue desempeñando una función radical en las éticas profesionales, no tanto por las dimensiones psicológicas o motivacionales de la ocupación que se realiza sino por las preguntas éticas que suscita. ${ }^{4}$

Los estudios de la población ocupada indican que todos los que tienen una ocupación quieren ser profesionales. Ahora bien, el hecho de que todos quieran ser profesionales hace que la tarea de definir las profesiones se convierta en fuente de agravios para las ocupaciones que no caen bajo la definición de profesión. Un concepto demasiado restringido de profesión puede descalificar ex definitione las pretensiones que muchas ocupaciones tienen de convertirse en profesiones. Por el contrario, sí considerásemos profesionales a todos aquellos que tienen una ocupación estable, entonces ensancharíamos el campo de

${ }^{4}$ Cfr. A. Cortina; J. Conill; A. Domingo; D. García-Marzá, "Ética de la dirección”, en Ética de la empresa. Claves para una cultura empresarial, 1994, Madrid, Trotta. 
nuestra reflexión a lo que sería una ética del trabajo, una ética de la laboriosidad.

Así pues, y siguiendo el planteamiento de A. Hortal, partiremos de una definición tipológica de profesión. Una definición-tipo nos permite presentar una serie de rasgos con los que caracterizar y determinar qué estamos entendiendo por profesión. Si se dan todos los rasgos estaremos ante una profesión en sentido pleno, si alguno falta o se cumple en menor medida, no por ello hay que dejar de hablar de profesión, aunque sea en un sentido menos pleno. ${ }^{5}$

Las profesiones son aquellas actividades ocupacionales con los siguientes rasgos:

a) en las que de forma institucionalizada se presta un servicio específico a la sociedad,

b) por parte de un conjunto de personas (los profesionales) que se dedican a ellas de forma estable, obteniendo de ellas su medio de vida,

c) formando con los otros profesionales (colegas) un colectivo que obtiene o trata de obtener el control monopolístico sobre el ejercicio de la profesión,

d) y acceden a ella tras un largo proceso de capacitación teórica y práctica, de la cual depende la acreditación o licencia para ejercer dicha profesión.

\subsection{Vocación educativa y ética profesional}

En esta reflexión que hemos realizado sobre la vocación y la profesión ha llegado el momento de que nos preguntemos ¿dónde está la vocación en la profesión educativa? ¿cuándo decimos que un profesional de la educación está verdaderamente vocacionado? Es muy difícil elaborar un 'test de calidad vocacional', como si pudiésemos medir y cuantificar el grado de vocación de quienes trabajamos en la educa-

${ }^{5}$ A. Hortal, op. cit., p. 207. 


\section{AGUSTÍN DOMINGO}

ción. Como en el resto de éticas profesionales, la vocación sólo se va descubriendo a medida que se ejerce. Nadie está cualificado 'a priori' para un determinado ejercicio profesional, es la práctica cotidiana la que despierta, confirma y refuerza la relación entre la profesión y el profesional.

Como en toda profesión, en el ámbito educativo es importante precisar los fines o bienes internos que la delimitan. A diferencia de la sociología de las profesiones, en la ética de las profesiones no nos preocupa únicamente ‘cómo son’ sino 'cómo deberían ser' los profesores. Este salto del nivel descriptivo al prescriptivo no es un salto en el vacío, como si entre los profesionales de la educación que realmente tenemos y los profesionales de la educación a los que idealmente aspiramos hubiese una distancia insalvable. Entre los profesionales de la educación realmente existentes hay muchos con una gran vocación que apenas si la han explicitado; son profesionales que muchas veces muestran más preocupación por los bienes internos que por los bienes externos.

La reflexión sobre los bienes internos de la profesión educativa ni ha ocupado ni ha preocupado a los teóricos de la educación. Más preocupados por los aspectos cuantitativos (extensión de la obligatoriedad, ratios, recursos económicos, medios, etc.), y más ocupados en las exigencias propias de la carrera profesional, los propios profesionales de la educación han descuidado los factores que posibilitarían una ‘remoralización’ de su actividad. Estas justas preocupaciones y lógicas ocupaciones no son una razón suficiente para dejar la pregunta por los bienes internos fuera de la reflexión moral. Y quedan fuera de la reflexión moral cuando se considera que la clarificación de los bienes internos es un tema individual o psicológico, como si la lucha contra el desencantamiento, el desánimo y la desmoralización de los profesionales de la educación se pudiera solucionar aumentando el número de terapeutas.

Entre el profesor real y el profesor ideal se encuentra el 'buen profesor', el que enseña bien y por eso consigue que los alumnos aprendan. Éste es el bien interno que aparece en las prácticas educativas. El 
ÉTICA DE LAS PROFESIONES

buen profesor no es una figura ideal que haya salido de ningún laboratorio educativo, tampoco es aquel que se conforma con cualquier práctica, sino el que mantiene una inquietud, una tensión, un deseo de inconformismo con la propia práctica, que realiza un esfuerzo de perfeccionamiento permanente. A nuestro juicio, es la pregunta por la 'vocación educativa' la que permite mantener esta tensión e inquietud en las prácticas. Para ello, es importante realizar ciertas distinciones:

\section{Ética del trabajo}

Ocupación, labor, trabajo

Perspectiva de la necesidad

\section{Tener un Empleo}

Hacer 'algo'

Emplear 'un' tiempo en una ocupación por medio de la cual:

- se obtienen unos recursos económicos

- se satisfacen unas necesidades materiales

\section{Ejercer una Profesión}

Coherencia y equilibrio entre bienes externos y bienes internos

Coordinación ética de fines y ética de medios

Unidad proyecto de vida y proyecto profesional

\section{Ética de las profesiones \\ Vocación profesional \\ Perspectiva de la libertad}

\section{Ejercer una Profesión}

Hacer-'se' alguien

Emplear-'se' en el tiempo, el tiempo no es externo al proyecto, es el propio proyecto de vida:

- se obtiene un reconocimiento social y autoestima

- identidad profesional y personal

\section{Ejercer una Carrera}

Reglas de acceso, ascenso, prestigio y promoción

Actividad condicionada por el éxito, el triunfo, la competitividad

Importancia del cálculo y riesgo de subordinar una ética de los medios a una ética de los fines

Cálculo de dinero, autoestima, prestigio, poder, reconocimiento, etc.

Parcelación y fragmentación de la vida social

La ética de las profesiones nos puede ayudar a explicitar el factor vocacional de las profesiones, para ello hay una serie de factores a considerar: 


\section{AGUSTÍN DOMINGO}

A. ¿Qué relación hay entre la especialización técnica y la responsabilidad personal? ¿Cómo integrar en nuestro proyecto de vida la especialización profesional? Plantear la pregunta por la vocación es plantear la pregunta por la coherencia e integración de especialización técnica con proyecto personal.

B. ¿Qué relación hay entre la práctica profesional y la institución en la que se inscribe? ¿Cómo se relacionan el ejercicio profesional y la vida institucional? Plantear la pregunta por la vocación es plantear la pregunta por los límites de la 'autonomía' profesional para no ser devorado por la dinámica institucional.

C. ¿Qué relación hay entre los bienes internos de la profesión y la autorrealización personal? ¿Cómo integrar los mínimos profesionales públicamente exigibles y los máximos personales?

D. ¿Qué se entiende por excelencia profesional: el éxito, la culminación de la carrera? ¿Dónde está el óptimo profesional? Es necesario plantear la excelencia en términos de bienes internos y no en términos de bienes externos. La cuestión clave no es ‘¿cómo ser el mejor?’ sino ‘¿cómo hacerlo cada día mejor?’.

\section{3. ¿Ética profesional o deontología profesional?}

A veces aparecen como sinónimos los conceptos de ética profesional y deontología profesional, la primera se encargaría de explicitar lo ético (los bienes), mientras que la segunda tendría como función explicitar lo deontológico (los deberes). Mientras que la ética profesional plantea la pregunta por los bienes internos, la deontología profesional ofrece una serie de consideraciones éticas que se derivan del respeto a los derechos, legítimos intereses y puntos de vista de los colegas, los usuarios y clientes.

No todo lo bueno es exigible a todos. Por eso mismo hacen falta normas. Ellas buscan salvaguardar unos mínimos obligatorios exigibles a todos. Sin normas no hay ni universalidad ni igualdad en las exigencias. La deontología profesional se ocupa de estos mínimos 
ÉTICA DE LAS PROFESIONES

normativos obligatorios para todos los que ejercen la misma profesión. En palabras de Augusto Hortal:

La ética está referida a la conciencia de los individuos. La deontología se mueve preferentemente en el campo de los criterios compartidos por el colectivo profesional. Sin la perspectiva ética, la deontología carece de horizonte de referencia. Para justificar las normas hay que apelar a los bienes que se supone que pretende promover cada una de las diferentes profesiones. ${ }^{6}$

Tanto la ética profesional como la deontología se inscriben en el marco de una ética social. En realidad, esta ética social es el marco de moralidad mínima que se concreta y hace efectiva en cada uno de los ámbitos de las actividades humanas. Esta ética social abre la perspectiva en la que se articulan las múltiples necesidades e intereses con las posibilidades y recursos disponibles buscando criterios de justicia. De esta forma,

...se corrige la tendencia al corporativismo en que tienden a caer los planteamientos de la ética profesional cuando no se toma en cuenta esta perspectiva. Las profesiones, y con ellas la ética profesional, corren el peligro de constituir un grupo segregado, alejado de las necesidades sociales, para crear un mundo plenamente autónomo, al margen de lo que la sociedad necesita de ellas, o de la escasez de recursos con que cuenta para financiar sus actividades... La reflexión ética no se limita a hacer propuestas ideales; también tiene que reflexionar sobre las condiciones reales en que dichas propuestas tienen que llevarse a cabo. ${ }^{7}$

${ }^{6}$ A. Hortal, "La ética profesional en el contexto universitario”, Lección inaugural curso académico 94-95, Universidad de Comillas.

${ }^{7}$ Ibid. 


\section{AGUSTÍN DOMINGO}

Así pues, los conceptos de ética social, ética profesional y deontología profesional tienen que ser utilizados adecuadamente. Utilizaremos el concepto de ética social, entendida aquí como ética mínima, ${ }^{8}$ como el marco normativo mínimo necesario en el cual se integran las distintas actividades humanas. Esta ética mínima es condición necesaria pero no suficiente para el desarrollo de las éticas profesionales. Gracias a esta ética mínima hay un suelo común por el que circulan las éticas profesionales, hay un mínimo código de la circulación por el que pueden transitar las diferentes éticas y los diferentes proyectos de felicidad. Utilizaremos el concepto de ética profesional para explicitar los bienes internos, el telos de cada una de las profesiones, el conjunto de bienes desde los que dicha actividad cobra su sentido y valor. Utilizaremos el concepto de deontología profesional para explicitar las normas mínimas exigibles a un grupo de profesionales, normas que no sólo detallan las obligaciones que tienen los profesionales con respecto a la sociedad, sino que indican los mínimos que la sociedad puede y debe exigir a un grupo de profesionales.

\section{Una sociedad de profesionales ante la educación superior}

\subsection{De las utopías a las responsabilidades}

Si hasta aquí hemos sentado las bases conceptuales con las que nos guiaremos, ahora vamos a determinar qué le pide una sociedad de profesionales a la educación superior. En principio queremos señalar el hecho de que las inquietudes por el cambio social siempre son vehiculadas a través de determinados catalizadores. El hecho de que con la caída del muro de Berlín en 1989 se haya levantado acta de que han caído las ideologías o han muerto las utopías no significa que desde ese momento sean imposibles los proyectos de cambio social. Parece ser que 'las ideologías’, ‘las utopías’, e incluso ‘la Historia’ si nos atenemos al

${ }^{8}$ A. Cortina, Ética mínima, 1986, Tecnos, Madrid. 
ÉTICA DE LAS PROFESIONES

conocido artículo de Fukuyama El fin de la Historia, ya no son los vehículos más apropiados para el cambio y la transformación social. Sin embargo, conviene que no aceptemos acrítica y simplificadamente estos juicios, quizá sean demasiado precipitados.

Si las ideologías, las utopías e incluso la Historia -con mayúsculasson planteados como 'metarrelatos' (Lyotard) desde los que se construían los proyectos de cambio, los deberes sociales también se articulaban en torno a ellos. Entonces tenemos que preguntarnos si con la muerte de estos grandes metarrelatos se puede proclamar también ‘el crepúsculo del deber' (Lipovetsky). Aunque en un primer momento recibamos como saludable esta crisis de discursos pseudo-religiosos y con matices más o menos escatológicos, no deja de ser preocupante que esta crisis pueda ser interpretada como una 'crisis de la democracia’, más aún, como la imposibilidad de 're-generar', 're-moralizar' o reformar permanentemente unas democracias siempre perfeccionables.

Esta nueva situación ideológica ha generado un panorama como el siguiente:

a) tecnificación de las normas jurídicas; la reforma como una cuestión de técnica jurídica, recomposición de la 'neutralidad' de los sistemas democráticos.

b) desplazamiento de las utopías hacia otras direcciones: ecologismo, feminismo, pacifismo, nueva generación de derechos (ecología, paz).

c) privatización de la moral, restricción del deber al ámbito privado y familiar; lo que supone segmentar la vida moral en 'moral privada'/'moral pública'.

d) reconstruir las antropologías que sustentaban los metarrelatos y redefinir el deber en términos de responsabilidad.

Con independencia de que podamos añadir nuevas interpretaciones o completar las que aquí indicamos, lo que sí parece claro es la emergencia del concepto de 'responsabilidad' como catalizador del cambio social. Vaclav Havel quizá sea uno de los símbolos de estas revolu- 


\section{AGUSTÍN DOMINGO}

ciones de la responsabilidad como revoluciones de terciopelo cuando se ha atrevido a titular su autobiografía La responsabilidad como destino. ${ }^{9}$ Hans Jonas ha llegado ha formular un nuevo imperativo categórico para la nueva situación en su libro El principio responsabilidad. Una ética para la civilización científica y tecnológica. ${ }^{10}$ El propio Karl Otto Apel habla de la ética discursiva como una Macro-ética de la responsabilidad. ${ }^{11}$

Esta sustitución de las utopías por las responsabilidades es la que también se ha producido con el 'boom' de las éticas aplicadas. A partir de los años 70, y con el liderazgo de la bioética, ha cobrado protagonismo una nueva inquietud moral donde las reflexiones ideológicas, utópicas o históricas han dejado paso a nuevas reflexiones sobre los distintos ámbitos de actuación en que se desarrollan las actividades humanas. Esto ha supuesto una relectura de la distinción que Max Weber ofreció entre ‘ética de la convicción’ y ‘ética de la responsabilidad', como si a partir de ahora hubiésemos encontrado en esta última la clave para 're-moralizar' la vida social o 're-encantar' el mundo. ${ }^{12}$

La responsabilidad se ha convertido en el puente conceptual más apropiado para unir los grandes principios con las pequeñas situaciones, los programas institucionales con los proyectos personales, la capacitación y formación teórica con las exigencias de la práctica. A partir de ahora, y con independencia de las identidades corporativas que tengan las instituciones sociales o educativas hay una exigencia que se ha convertido en prioritaria: la exigencia de responsabilidad. No pensemos que la responsabilidad nos soluciona todos los problemas porque ¿cómo hay que entender la responsabilidad? ¿se trata únicamente de

${ }^{9}$ 1989, Madrid, El País-Aguilar, trad. A. Ortíz.

10 1994, Barcelona, Herder, trad. A. Sánchez Pascual.

${ }^{11}$ Diskurs und Verantwortung, 1992, Frankfurtt a.m., Suhrkamp.

${ }^{12}$ Véase nuestro artículo "Comunicación global y responsabilidad moral. La ética de la convicción en la sociedad de la información”, en V. A., Los retos de la sociedad de la información, 1998, Salamanca, Universidad Pontificia Salamanca, p. 110-21. 
ÉTICA DE LAS PROFESIONES

‘calcular consecuencias’? ¿estamos ante una vuelta del consecuencialismo moral? Aunque por ahora no respondamos a estas preguntas, sí parece claro el protagonismo de las responsabilidades en la sustitución de una sociedades ideologizadas por sociedades profesionalizadas.

\subsection{De sociedades ideologizadas a sociedades de profesionales}

Hace algunos años la Fundación Encuentro publicó el estudio sobre la sociedad española "Hacia una sociedad de profesionales". ${ }^{13}$ Más que una realidad, con el título estaba expresando una tendencia: la sociedad española se estaba convirtiendo en una sociedad de profesionales. Aunque los datos del informe hacían referencia únicamente a la sociedad española, se trataba de un análisis que también se había realizado en otros países europeos, lo que significa que la tendencia era compartida por las sociedades europeas en general. Con independencia de las reservas que nos pueda producir este tipo de estudios y su más o menos justa extrapolación a otras sociedades y contextos, nos interesa destacar la tendencia de análisis que muestran. Éste será el punto de partida con el que interpelaremos a las instituciones educativas, es decir, serán las conclusiones de este análisis social las que nos lleven a precisar y delimitar los retos y tareas que tiene planteados la educación superior.

Las conclusiones que aparecen en el informe son las siguientes:

1. Los profesionales tienen clara conciencia de su autonomía a la hora de tomar decisiones y asumir responsabilidades.

2. Ninguna profesión se considera 'para sí misma', el ejercicio profesional tiene una referencia a la alteridad social. Sin esta dimensión de alteridad es impensable la mejora en la calidad de las prácticas profesionales. Podríamos decir que se trata de una dimensión de servicio social que tiene todo ejercicio profesional ejercido con responsabilidad.

${ }^{13}$ España 1995, 1996, Madrid, Fundación Encuentro, p. 3-58. 


\section{AGUSTÍN DOMINGO}

3. Hay dos actitudes que son consideradas prioritarias para mejorar la calidad del servicio profesional: estar al día en las competencias profesionales y respetar a los clientes y ganarse su confianza.

4. Los profesionales están convencidos que los valores éticos mejoran la calidad profesional.

5. Todos los profesionales sitúan en el último lugar de su escala ideal de valores los beneficios económicos.

6. Las nuevas responsabilidades con las que se encuentran los profesionales se encuentran en una encrucijada:

- La dirección que marca la fidelidad a los antiguos códigos profesionales de las deontologías clásicas. Decisión moral como deducción moral. Los profesionales piden consejo a los colegios profesionales.

- Las exigencias de las nuevas tecnologías que plantean con rapidez nuevos problemas sin apenas posibilidades para deliberar. Se impone una acción sin deliberación. Escasa referencia a principios, atención a la inducción y casuística. Los profesionales exigen protocolos de actuación para decidir con rapidez.

- El valor de la autonomía profesional ha reforzado la función de la conciencia. La fidelidad a la propia conciencia moral desde la que se inicia un proceso de búsqueda, que puede ser individual o grupal.

7. Se sientan así las bases de una nueva razón práctica a la que deben ir respondiendo las nuevas éticas aplicadas porque:

- Aunque haya fidelidad y continuidad con los usos y normas de la profesión, se asiste a modos personales de interpretación. Se tratará de una fidelidad personalmente interpretada que muestra las insuficiencias de una razón práctica deductiva. 


\section{ÉTICA DE LAS PROFESIONES}

- El profesional se ve obligado a responder a la imagen que la sociedad se ha creado de él. Esta imagen plantea nuevos problemas de identificación porque los profesionales no se ajustan con facilidad a las expectativas depositadas en las imágenes tradicionales.

8. Aparecen dos tendencias dentro de los propios profesionales:

- A la adaptación y al conformismo. Se prefiere cumplir con las normas establecidas por la propia profesión, por los propios países y por las propias instituciones en las que se trabaja.

- A la creatividad. Motivados por un fuerte sentido de la autonomía moral y por la atención que prestan a las necesidades de justicia, muchos profesionales apuestan por soluciones innovadoras. La innovación no es necesariamente ruptura ni enfrentamiento con las normas establecidas, pero sí supone un nuevo modo de entender la profesionalidad, que no es el tradicional.

2.3. Instituciones educativas en una sociedad liberal. ¿servicios de aprendizaje o comunidades de identificación?

Ante esta situación no pueden permanecer al margen las instituciones educativas. ¿Qué tipo de profesionales tienen que formar: fieles a los antiguos códigos o a la propia conciencia? ¿Se tienen que ajustar a las demandas del mercado laboral? ¿Pueden aportar elementos de discernimiento para afrontar esta encrucijada? ¿Cuál es el perfil ético deseable en una sociedad liberal? ¿Cómo interviene el ideario de un centro educativo en la modulación de este perfil?

Para responder a estas preguntas es importante que nos tomemos en serio la identidad de las instituciones. Puesto que nuestro trabajo como educadores se desarrolla dentro de un marco institucional, vamos a preguntarnos qué es lo que lo diferencia de otros centros. No es una cuestión que incumba sólo a la oferta privada de centros educativos, 


\section{AGUSTÍN DOMINGO}

es también una cuestión que atañe a los centros públicos. Hasta ahora habíamos creído que la identificación sólo era necesaria en centros privados que ofrecían una oferta diferenciada en el mercado. Sin embargo, también es un problema para los centros públicos. Aunque teóricamente los centros educativos públicos garanticen formalmente los mismos servicios y ofrezcan unos estudios de calidad homogénea, en la práctica cada centro tiene una historia diferente, un equipo diferente de profesores y un perfil diferenciado de alumnado. Por eso, aunque teóricamente la identidad o el ideario no sea un problema, sí lo es desde un punto de vista práctico porque de hecho toda institución educativa es, también, un centro de identificación.

Esta idea ha sido desarrollada en profundidad por el filósofo Charles Taylor. Con ocasión del L Aniversario de la creación de la Facultad de Ciencias sociales de la Universidad de Laval, en 1988 dictó una conferencia que se publicó más tarde en la revista Esprit y que llevaba por título "Las instituciones en la vida nacional”. ${ }^{14}$ En su análisis de la vida institucional toma dos paradigmas extremos de instituciones: la familia y las estaciones de servicio. Pero antes de mostrar las características de estos dos tipos de instituciones extremas, indica la relación que existe entre vida moral y vida institucional. Según Taylor:

Una práctica, con su normatividad implícita, puede encarnar una moral o un ideal. Puede constituir la primera definición de una moral, sea porque no hay ninguna definición establecida, sea que es mucho menos rica y concreta que la moral vivida. Así la institución se convierte en la formalización de una práctica. La institución no es el punto de aplicación de una moral definida desde fuera, sobre todo es el medio donde la moral se elabora. En tanto que vehículo primero de esta visión de la vida, constituye un polo importante de identificación para quienes participan en ella. ${ }^{15}$

${ }^{14}$ Esprit, 200, 1984, p. 90-103.

${ }^{15}$ Ch. Taylor, op. cit., p. 92-3. 


\section{ÉTICA DE LAS PROFESIONES}

Desde aquí pasa a distinguir los dos tipos de instituciones:

Hay estructuras donde la relación con nuestra vida tan sólo es instrumental, incluso si el servicio que ellas nos ofrecen es importante y hay, por otra parte, medios donde la frecuentación es para nosotros el lugar primario de definición de los valores importantes, y por tanto, de polos posibles de identidad. Hay, por tanto, instituciones de servicios, de un lado, e instituciones identificadoras, por otro... según una concepción extendida de modernización, ésta consiste en parte en un desplazamiento de éstas hacia el lado del servicio... La modernización, acompañada por la secularización, desacraliza el estado, reemplaza las instituciones religiosas por estructuras laicas y se preocupa cada vez más por su rendimiento. Al mismo tiempo, la sociedad se diversifica; se acentúa el pluralismo social y religioso. Las instituciones tradicionales ya no tienen el mismo significado para todo el mundo. Pero hay una segunda variación: ciertas estructuras guardan su significación identificatoria para ciertas personas, mientras que para otras se transforman en simples dispensadoras de servicios. ${ }^{16}$

La modernización de las instituciones exige un nuevo equilibrio en el estado laico pluralista, equilibrio que se define alrededor de un nuevo reparto de funciones: las instituciones que guardan una dimensión identificadora son calificadas como privadas, es decir, que la adhesión de sus miembros es voluntaria. Por el contrario, las instituciones públicas se convierten en estructuras de servicios no sólo importantes sino esenciales, aunque sin ninguna dimensión identificadora.

Pero el estado moderno no es sólo una institución de servicios, este análisis de la modernización olvida una dimensión importante del estado moderno, se trata de un estado-nación. La lengua, la cultura y las formas políticas son las que garantizan la cohesión. Un estado

${ }^{16}$ Ibidem, p. 93-4. 


\section{AGUSTÍN DOMINGO}

entendido únicamente como institución de servicios, sin ningún tipo de patriotismo, sería un peligro de disgregación. Según la tendencia a entender el estado como estado neutral, "los valores que encarna el estado deben ser únicamente procedimentales, definir las reglas de justicia, pero ninguna moral teleológica (cfr. Rawls)". ${ }^{17}$

¿Cómo conciliar las necesidades de identificación con la tendencia de las instituciones públicas en una sociedad moderna y pluralista hacia la reducción de instituciones públicas como instituciones de servicio?

Taylor se resigna a la tesis liberal antes expuesta de que sean las instituciones privadas las que faciliten la identificación. No restringe la función identificadora a las instituciones privadas ahora desprovistas de toda misión de agrupamiento. La función identificadora no puede ser excluida del dominio público. Taylor habla de 'vocación nacional' de las instituciones públicas y describe como se ha desplazado a medida que las instituciones públicas acaban convirtiéndose en instituciones de servicio. Plantea el tema de la ‘autodescripción compartida’ y señala que a partir de ahora "ya no podemos tener la identidad nacional como una cosa adquirida, dada y definida”. Para él esta identidad y sus fines tienen que negociarse a partir de perspectivas diversas y difícilmente conciliables. En este contexto, la idea misma de una asociación que pretendiera obrar como lugar de agrupamiento en nombre de todos ¿qué sentido tendría?

Pero no todo ha cambiado; sigue manteniendo una concepción no meramente instrumental, de matriz aristotélica, donde la política sea entendida como expresión de los ciudadanos libres, y esto será una parte integrante de una identidad nacional en vías de perpetua definición.

Taylor pretende que el dominio político conserve un lugar importante en el proceso de autoidentificación, que crezca en la misma medida en que otras instituciones pierden su función identificadora. Y no se trata de un simple desplazamiento, sino que el trabajo de autodefinición se transforma. También da dos tipos ideales de identificación:

${ }^{17}$ Ibid., p. 95. 
- vida nacional con presunción de unanimidad, donde muchas instituciones pueden encontrar vocación nacional.

- vida nacional fundada sobre la diversidad, donde el proceso político revela una significación crucial, no sólo como instrumento de autodefinición, sino como el mayor elemento de una identidad constituida en gran parte por un debate indefinido y sin cierre definitivo entre pluralidad de opciones legítimas (permanente 'equilibrio reflexivo').

Si aplicamos estas reflexiones de Taylor a los centros educativos hay una serie de consideraciones que no pueden pasarse por alto.

A. La función, el papel o rol de todos los miembros de la comunidad educativa se realiza en el interior en unas prácticas cuyo significado se comparte.

B. La formalización de estas prácticas convierte un centro educativo en una 'institución’ educativa. La formalización no debe ser entendida aquí en términos de 'diseño formal' o 'matemático’, como si fuese algo previo y anterior a la realización de las prácticas. La institución no es ‘un medio’ para conseguir determinados 'fines' morales que acompañan cada una de las prácticas. La institución es ‘el medio’ sin el cual no habría ni fines, ni prácticas, ni vida moral.

C. Con la modernización los procesos institucionales tienen a instrumentalizarse, de manera que se pone en cuestión el carácter finalista de las instituciones. Esto no significa que todas las instituciones se transformen en instrumentales, 'medios' públicos disponibles para 'fines' privados voluntarios.

D. Puesto que las instituciones públicas tienden a convertirse en instituciones de servicios y han dejado las tareas de identificación a las instituciones privadas, se plantea el problema de las instituciones 'nacionales' 


\section{AGUSTÍN DOMINGO}

Taylor aplica este proceso al ‘estado’, pero también lo podemos aplicar a la universidad`¿cuál debe ser la identidad de un centro educativo 'nacional'? ¿será un centro educativo 'neutral'? ¿qué tipo de compromisos lo definen? ¿es tan sólo una institución de servicios? ¿hay algún servicio que lo defina con respecto a otras instituciones públicas? ¿está obligado a perder su identidad nacional si quiere ofrecer algún tipo de identidad corporativa? Para responder a estas preguntas quizá convenga tener presente:

- la relación entre institución y vida moral

- la formalización como un proceso dinámico y público

- la 'vocación nacional' como vocación de cohesión social, de autodescripción compartida y de equilibrio frágil de identidades

- la responsabilidad política de las instituciones públicas como espacios de diálogo y cooperación social donde ya no es posible la unanimidad moral y donde no es deseable el atomismo diversificador

2.4. La misión de la Universidad. Cultura, profesión y ciencia

Si deseamos responder a los desafíos que nos tiene planteados la Universidad debemos recordar permanentemente la misión de la universidad. Y recordar no es algo pasivo que le sucede al hombre, que le pasa, sino que él hace. Como diría Ortega: “Conmemorar es recordar en comunidad y públicamente: la conmemoración es la solemnidad del recuerdo" ${ }^{18}$ Pero no se trata ahora de conmemorar un acontecimiento, sino de recuperar este carácter activo del recuerdo y aplicarlo a la 'misión' de la Universidad. Para acertar en cualquier proyecto de reforma es importante tener presente esta misión. Para ello, Ortega nos advierte: “...la escuela, como institución normal de un país, depende

18 J. Ortega y Gasset, "En el Centenario de una Universidad”, en Misión de la Universidad, 1997, Madrid, Alianza, p. 173. 
mucho más del aire público en el que íntegramente flota que del aire pedagógico artificialmente producido dentro de sus muros”. ${ }^{19}$

En este sentido, no se trata tanto de implantar el modelo inglés, americano, alemán o francés, se trata de tener claro en qué consiste la enseñanza universitaria. A su juicio no puede consistir en unir dos tareas muy diferentes: la enseñanza profesional que es para muchos y la investigación que es para poquísimos. Asimismo hay una dimensión cultural sin la cual no podríamos hablar de 'universidad'.

I. Transmisión de la cultura.

II. Enseñanza de las profesiones.

III. Investigación científica y educación de nuevos hombres de ciencia.

Esta dimensión cultural no es un conjunto de informaciones de carácter ornamental con los que los licenciados pueden presumir de ciertos conocimientos históricos, literarios o sociales, como si la cultura fuera una dimensión decorativa del espíritu humano. Una cosa es ser sabio o especialista y otra cosa es ser culto. La cultura no puede ser sino 'general':

'Cultura general': cultura, referida al espíritu humano -y no al ganado o a los cereales- no puede ser sino 'general'. No se es culto en física o matemáticas. Eso es ser ‘sabio’ en una materia. Al usar esta expresión de ‘cultura general’ se declara la intención de que el estudiante reciba algún conocimiento ornamental y vagamente educativo de su carácter o de su inteligencia. (...) No hay remedio: para andar con acierto en la selva de la vida hay que ser culto, hay que conocer su topografía, sus rutas o 'métodos'; es decir, hay que tener una idea del espacio y del tiempo en el que se vive, hay que ser actual. ${ }^{20}$

${ }^{19}$ Ibid., p. 28.

${ }^{20}$ Ibid., p. 34, 40. 


\section{AGUSTÍN DOMINGO}

Al posibilitar la orientación del hombre en el mundo, ante 'la selva de la vida', la cultura ya no tiene un carácter ornamental o instrumental, sino radical. La cultura permite entender unitariamente al hombre, hacer que el ser humano no esté roto en los pedazos del especialismo o las profesiones. La cultura permite situar, ubicar y enraizar tanto la especialidad como la profesión:

El especialismo y el profesionalismo, al no ser debidamente compensados, han roto en pedazos al hombre europeo, que por lo mismo está ausente de todos los puntos donde pretende y necesita estar. En el ingeniero está la ingeniería, que es sólo un trozo y una dimensión del hombre europeo; pero éste, que es un integrum, no se halla en su fragmento 'ingeniero'. (...) La cultura irá fomentando un género de talento científico que hasta ahora sólo se ha producido por azar: el talento integrador. Significa éste una especialización; pero aquí el hombre se especializa precisamente en la construcción de una totalidad. Y el movimiento que lleva a la investigación al disociarse indefinidamente en problemas particulares, al pulverizarse, exige una regulación compensatoria mediante un movimiento de dirección inversa que contradiga y retenga en un vigoroso sistema la ciencia centrífuga. ${ }^{21}$

Así pues, la misión se la universidad se concreta en:

I. La Universidad consiste, primero y por lo pronto, en la enseñanza superior que debe recibir el hombre medio.

II. Hay que hacer del hombre medio, ante todo, un hombre culto -situarlo a la altura de los tiempos. Por tanto, la función primaria y central de la Universidad es la enseñanza de las grandes disciplinas culturales. ${ }^{22}$

${ }^{21}$ Ibid., p. 40 y 72.

${ }^{22}$ Ibid., p. 53. 
ÉTICA DE LAS PROFESIONES

Para Ortega tampoco hay que olvidar la relación que tiene existir entre la investigación científica y la enseñanza profesional. No se puede pretender hacer de todo estudiante universitario un científico:

Sin duda el aprendizaje profesional incluye muy principalmente la recepción del contenido sistemático de no pocas ciencias. Pero se trata del contenido, no de la investigación que en él termina. En tesis general, el estudiante o aprendiz normal no es un aprendiz científico. (...) Ha sido desastrosa la tendencia que ha llevado al predominio de la ‘investigación’ en la Universidad. Ella ha sido la causa de que se elimine lo principal: la cultura. Además, ha hecho que no se cultive intensamente el propósito de educar profesionales ad hoc. En las facultades de medicina se aspira a que se enseñe hiperexacta fisiología...; pero tal vez en ninguna del mundo se ocupa nadie en serio de pensar qué es hoy ser un buen médico, cuál debe ser el tipo modelo de médico actual. La profesión, que después de la cultura es lo más urgente, se deja a la buena de Dios. (...) La pedantería y la falta de reflexión han sido grandes agentes del cientificismo que la Universidad padece. (...) Hay, pues, que sacudir bien de ciencia el árbol de las profesiones, a fin de que quede de ella lo estrictamente necesario, y pueda atenerse a las profesiones mismas cuya enseñanza se halla hoy completamente silvestre. ${ }^{23}$

Las relaciones entre la cultura y la ciencia tampoco pueden ser olvidadas. La cultura extrae de la ciencia lo vitalmente necesario para interpretar nuestra existencia; no toda la ciencia es cultura, hay una gran parte de la ciencia que es pura técnica científica. La cultura necesita poseer una idea completa del mundo y del hombre. Además se trata de una posesión existencialmente necesaria, dada la perentoriedad de la vida. Si la ciencia puso orden en la vida, ahora exige Ortega

${ }^{23}$ Ibid., p. 57-9. 


\section{AGUSTÍN DOMINGO}

que la vida ponga orden en la ciencia, que la vitalice, "que la haga compatible con la vida humana que la hizo y para la cual fue hecha".24 Esto exige no confundir dos tareas importantes, la de saber y la de investigar:

\section{Investigar}

Descubrir una verdad o su inverso, demostrar un error.

\section{Saber}

Enterarse bien de esa verdad, poseerla una vez hecha, lograda.

\subsection{El verdadero poder de la Universidad. Comunidad de memoria viva}

Al final de su ensayo sobre la misión de la Universidad, Ortega reconoce que ésta no sólo debe estar orientada a la cultura, la ciencia o las profesiones. Exige que la Universidad esté abierta a los problemas de la calle, con la realidad histórica, con el presente, "que es siempre integrum y sólo se puede tomar en totalidad, sin amputaciones (...) tiene que estar abierta a la plena actualidad; más bien, tiene que estar en medio de ella, sumergida en ella”. ${ }^{25}$

Ahora bien, para mantenerse abierto a la actualidad, la Universidad tiene qué tomar conciencia de dónde se encuentra su verdadero poder. Al sumergirse en la actualidad puede ser arrastrada por la corriente de las opiniones políticas, de los grupos de comunicación o de cualesquiera otros poderes. Su verdadero poder es espiritual: “...metida en medio de la vida, de sus urgencias, de sus pasiones, ha de imponerse como un poder espiritual superior frente a la prensa representando la serenidad frente al frenesí, la seria agudeza frente a la frivolidad y la franca estupidez". ${ }^{26}$

Para conseguir mantenerse como poder espiritual, la Universidad no puede conformarse con ser un 'grupo', una ‘agrupación', un 'mosaico'

${ }^{24}$ Ibid., p. 71.

${ }^{25}$ Ibid., p. 77.

${ }^{26}$ Ibid., p. 78-9. 
ÉTICA DE LAS PROFESIONES

o un ‘conglomerado' de intereses dispersos. Este poder espiritual que es un poder de resistencia y de integridad se consigue planteando la Universidad como una 'comunidad de memoria'.

Utilizaremos este término en contraposición a 'enclave de estilo de vida’. Estos dos conceptos han sido utilizados por N. Bellah y su grupo de investigadores cuando han analizado el individualismo de la sociedad estadounidense. ${ }^{27}$ En una cultura individualista, los enclaves de estilo de vida son espacios en los que los individuos comparten su tiempo de ocio. Ser socio de un club de tenis, de un casino o de un gimnasio es un modo de relacionarse voluntaria e individualmente. Lo que une a los socios de estas agrupaciones es una afición, una parte de su tiempo, un hobbie, un aspecto parcial de la vida. En la sociedad individualista, formar parte de este tipo de asociaciones es una manera de mantener cierto espíritu comunitario, por débil, pobre y fragmentario que sea. Los socios de estas agrupaciones, reconocen que juntos realizan mejor los fines que cada uno persigue.

Cuando los individuos no comparten aspectos parciales de su vida sino fundamentales, la agrupación adquiere más solidez comunitaria y puede llegar a formarse una comunidad de vida. Cuando un grupo de personas que padecen una misma enfermedad se asocian para defender sus intereses y esta asociación se convierte en una asociación de autoayuda, las relaciones que se generan entre los miembros acaban siendo relaciones fuertes, es decir, relaciones en las que los lazos o vínculos son fundamentales en la definición de la identidad de cada persona. En las sociedades liberales donde triunfa una cultura individualista, las comunidades de memoria se están convirtiendo en referencias éticas fundamentales en la vida social. ${ }^{28}$

Los enclaves de estilo de vida son algo parecido a las estaciones de servicio de las que nos hablaba Charles Taylor. Las comunidades de

${ }^{27}$ Cfr. Hábitos del corazón, 1988, Madrid, Alianza.

${ }^{28}$ Sobre esta relación entre ‘enclaves de estilos de vida’ y ‘comunidades de memoria’ aplicado a las asociaciones voluntarias, puede verse nuestro trabajo Ética y voluntariado. Una solidaridad sin fronteras, 1997, Madrid, PPC. 


\section{AGUSTÍN DOMINGO}

memoria también guardan cierto parecido a las instituciones de identificación a las que nos hemos referido anteriormente. Pues bien, quizá haya llegado la hora de preguntarse dónde se sitúa la institución universitaria en esta topografía institucional. El problema más que resuelto sólo está planteado. A lo largo de estas páginas hemos proporcionado algunas pistas al respecto, sobre todo cuando nos planteamos la necesaria y urgente dimensión cultural que necesita la vida universitaria. Ahora sólo nos queda preguntamos si cuando hablamos de 'modernizar’ la Universidad estamos preguntándonos por la cultura, la investigación científica o la proyección hacia la vida profesional. Pero ésa es una tarea que debemos dejar para mañana.

\section{Conclusiones y desafíos}

1. Ante la educación superior las éticas profesionales no reclaman una profesionalización de la vida universitaria sino una reordenación de los fines profesionales, laborales, culturales y sociales de la Universidad. Esta reordenación, no supone una tecnificación de las enseñanzas o una instrumentalización de las programaciones académicas, sino una incentivación de la búsqueda de los bienes internos propios de las actividades profesionales.

2. Ante la autonomía creciente que tienen los profesionales la responsabilidad que tienen las instituciones universitaria es mayor. Sustentar habilidades en la capacitación teórica y la tutela para la capacitación práctica exigen que la universidad lidere un nuevo modelo de razón práctica, exigen que la universidad lidere un nuevo modelo de razón práctica, dado que los grandes principios lógicos de la casuística son insuficientes para esclarecer la encrucijada en la que se encuentran los profesionales creativos.

3. La éticas profesionales son también aplicables para la práctica de la enseñanza universitaria. La pregunta por la vocación del docente universitario no es una pregunta baladí, sino la posibilidad de introducir 
ÉTICA DE LAS PROFESIONES

una reflexión profunda de la identidad moral en la que se encarna la vida institucional.

4. Las sociedades modernas y democráticas exigen un modelo de universidad pública que también proporcione elementos de la identificación institucional. Esta identificación no se consigue únicamente con la promoción, con investigación científico-técnica o la docencia, sino con una dimensión cultural que aporte la perspectiva de una capacitación vital e integral.

5. Las éticas profesionales exigen unos alumnos universitarios sumergidos en la actualidad. Esta inmersión en la actualidad no sólo permite identificar los valores de una democracia liberal, sino mantener una opinión pública despierta y corresponsable ante la cada vez más apremiante determinación informativa de la realidad y de la variedad de la información; esta inmersión de la universidad en la actualidad puede ejercer un liderazgo importante para conseguir que las instituciones públicas además de facilitar servicios faciliten prácticas de identificación comunitaria. 
